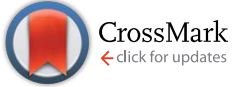

Received 18th December 2016 Accepted 17th January 2017

DOI: 10.1039/c6ra28351a

www.rsc.org/advances
Cite this: RSC Adv., 2017, 7, 8280

\section{The degradation and persistence of five pharmaceuticals in an artificial climate incubator during a one year period $\dagger$}

\author{
Lina Yin, ${ }^{\text {ab }}$ Ruixue Ma, ${ }^{a}$ Bin Wang, ${ }^{* a}$ Honglin Yuan ${ }^{b}$ and Gang Yu ${ }^{a}$
}

The degradation and persistence of the five pharmaceuticals atenolol, metoprolol, propranolol, fluoxetine and venlafaxine at an initial concentration of $10 \mathrm{mg} \mathrm{L}^{-1}$ was studied at different $\mathrm{pH}$ values under fluorescent light and darkness in an artificial climate incubator during a one-year period. The results suggested that the degradation process of the target pharmaceuticals followed pseudo first-order degradation kinetics. Propranolol was degraded at a higher rate, with a half-life ranging from 5.7 to $28.5 \mathrm{~d}$. The degradation rates of propranolol and venlafaxine increased with increasing $\mathrm{pH}$ value, while the other pharmaceuticals did not show a clear $\mathrm{pH}$ correlation, with the highest degradation rate at $\mathrm{pH} 7$ for atenolol, $\mathrm{pH} 2$ for metoprolol and $\mathrm{pH} 12$ for fluoxetine. Both photodegradation and hydrolysis should contribute to the degradation. Typical transformation products were detected and were identified as metoprolol acid, $\alpha$ hydroxymetoprolol, norfluoxetine and $O$-desmethylvenlafaxine. The findings could not only help to understand the degradation and fate of pharmaceuticals but also provide the fundamental data for persistence assessments.

\section{Introduction}

In recent years, due to their incomplete removal during a series of physical, chemical and biological transformation processes in municipal sewage treatment plants (STPs), pharmaceuticals have been subsequently released into the aquatic environment. $\beta$-Blockers, such as atenolol, metoprolol and propranolol, as well as antidepressants, such as fluoxetine and venlafaxine were frequently detected in wastewater effluents ${ }^{1,2}$ and surface water, ${ }^{3-7}$ even in drinking water. ${ }^{8,9}$ Pharmaceuticals were identified in surface water at concentrations of $\mathrm{ng} \mathrm{L}^{-1}$ to $\mu \mathrm{g} \mathrm{\textrm {L } ^ { - 1 } \cdot { } ^ { 1 0 }}$ This has caused global concerns due to the adverse ecological effect towards non-target aquatic organisms even at low concentrations. Schultz et al. ${ }^{4}$ found that fluoxetine was present in fish brain tissue in two U.S. effluent-impacted streams. Venlafaxine and its metabolites can affect the central nervous system, disrupt neuron-endocrine signalling, and alter the reproduction patterns of aquatic organisms. ${ }^{11}$ Additionally, the toxic effects of $\beta$-blockers to Daphnia magna were also investigated by other studies. ${ }^{12,13}$

${ }^{a}$ Beijing Key Laboratory of Emerging Organic Contaminants Control, State Key Joint Laboratory of Environmental Simulation and Pollution Control, Collaborative Innovation Centre for Regional Environmental Quality, School of Environment, Tsinghua University, Beijing, 100084, China. E-mail: thuwb@tsinghua.edu.cn ${ }^{b}$ School of Environmental and Municipal Engineering, Xi'an University of Architecture and Technology, Xi'an 710055, China

$\dagger$ Electronic supplementary information (ESI) available. See DOI: 10.1039/c6ra28351a
Generally, the removal of pharmaceuticals in surface water consists of biotic and abiotic process. Some pharmaceuticals, however, have been designed to be resistant to biodegradation. ${ }^{14}$ In addition, given pharmaceuticals discharged into surface water have already escaped the biodegradation environment of STPs, ${ }^{15}$ photodegradation and hydrolysis are two important dissipation pathways in natural water body. In the last decade, an increasing number of studies about the photodegradation of pharmaceuticals in natural water ${ }^{16-19}$ ultrapure water ${ }^{17,20}$ as well as wastewater effluents ${ }^{21}$ under solar or UV irradiation were performed. Rúa-Gómez et al. ${ }^{16}$ reported that half-lives of venlafaxine in ultrapure water $(\mathrm{pH}=6.9)$ at $\mathrm{Hg}$ lamp and sunlight radiation were $9.1 \mathrm{~d}$ and $19.6 \mathrm{~d}$, respectively. Propranolol was found to be degraded by xenon lamp ( $41 \mathrm{~W}$ $\mathrm{m}^{-2}$ ) in deionized water, with a half-life about $16 \mathrm{~h}^{22}$ Yamamoto et $a .^{20}$ also conducted photolysis experiments exposed to sunlight, and found atenolol was more persistent, with a halflife 87 times greater than that of propranolol.

Environmental degradation property is very important for us to understand the fate of pharmaceuticals in environment and wastewater. However, most previous photodegradation was performed under strong light intensity, ${ }^{14,15}$ and the research timescale is much shorter compared with their real environmental degradation time, and the degradation under artificially strengthened condition in previous studies is much quicker than environmental degradation rate. ${ }^{23}$ The study of long-term degradation under gentle condition is very scarce. Therefore, this study aimed to investigate the degradation and persistence of selected pharmaceuticals in ultrapure water under gentle 
conditions during one year, and to help evaluate their degradation characteristics in environment and wastewater. Some typical transformation products (TPs) were also analysed.

\section{Experimental}

\subsection{Materials and reagents}

Parent pharmaceutical standards (atenolol, metoprolol, propranolol, fluoxetine, venlafaxine), and their transformation product standards (metoprolol acid, $\alpha$-hydroxymetoprolol, norfluoxetine, $O$-desmethylvenlafaxine and desmethylvenlafaxine) were purchased from Sigma-Aldrich (Steinheim, Germany). The physicochemical properties and molecular structures of parent pharmaceuticals are listed in Table 1, the information of corresponding main TPs are listed in Table S2 (ESI $\dagger$ ). Methanol and formic acid were provided by Fisher Scientific (Loughborough, Leicestershire, UK). Ammonium acetate was obtained from Fluka (Buchs, Switzerland). All chemicals and solvents were of analytical grade and ultrapure water was produced by using a Milli-Q unit (Millipore, USA). Each pharmaceutical stock solution was prepared in methanol at $10000 \mathrm{mg} \mathrm{L}^{-1}$ and stored at $4{ }^{\circ} \mathrm{C}$ in the dark prior to use.

\subsection{Photodegradation incubation}

The photodegradation experiment under irradiation of visible light was conducted at an artificial climate incubator (BIC-400, Shanghai Boxun Industry \& Commerce Co., Ltd, China). Fluorescent lamp $(30 \mathrm{~W} \times 12)$ was used as light source. The parameters inside the incubator were originally set as follows: temperature $25{ }^{\circ} \mathrm{C}$, humidity $60 \%$ and illumination $100 \%$. The radiant parameters were measured directly by digital luxmeter (TENMARS TM-208, Taiwan): for illumination light: 4280 lux, UVA light power intensity: $0.17 \mathrm{~W} \mathrm{~m}^{-2}$ and solar light power intensity: $9.65 \mathrm{~W} \mathrm{~m} \mathrm{~m}^{-2}$. The absorption spectra of target compound solutions under different $\mathrm{pH}$ values were determined using Hach DR-5000 UV-vis spectrophotometer (see ESI $\dagger$ ). As shown in Fig. S3, $\dagger$ all the target compounds showed little or even negligible absorbance at light wavelengths above $350 \mathrm{~nm}$. Significant absorbance occurred between $200 \mathrm{~nm}$ and $300 \mathrm{~nm}$.

Each pharmaceutical was separately spiked into $300 \mathrm{~mL}$ ultrapure water at initial concentration of $10 \mathrm{mg} \mathrm{L}^{-1}$ and placed in $500 \mathrm{~mL}$ beakers. $\mathrm{pH}$ values were adjusted to $2,4,7,10,12$ with $1 \mathrm{~mol} \mathrm{~L}{ }^{-1} \mathrm{NaOH}$ or $\mathrm{HCl}$ solutions to maintain desired values during experimental process. $0.5 \mathrm{~mL}$ samples were taken

Table 1 Summary of physicochemical properties of selected pharmaceuticals

\begin{tabular}{lll}
\hline Therapeutic classification & $\beta$-Blockers & Metoprolol \\
\hline Pharmaceutical & Atenolol & MTP \\
Acronym & $\mathrm{ATN}$ & $37350-58-6$ \\
$\mathrm{CAS}$. No. & $29122-68-7$ & $\mathrm{C}_{15} \mathrm{H}_{25} \mathrm{NO}_{3}$ \\
Molecular formula & $\mathrm{C}_{14} \mathrm{H}_{22} \mathrm{~N}_{2} \mathrm{O}_{3}$ & 267.4 \\
$\mathrm{MW}$ & 266.3 & \\
$\mathrm{p} K_{\mathrm{a}} ; \log K_{\mathrm{Ow}}$ & $9.6 ; 0.61$
\end{tabular}

Ref.

24

25
Propranolol
PHO
525-66-6
$\mathrm{C}_{16} \mathrm{H}_{21} \mathrm{NO}_{2}$
259.3
$9.42 ; 3.48$

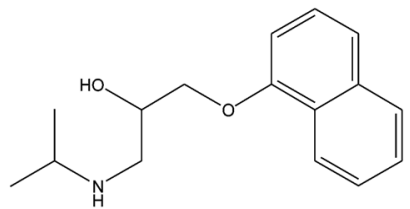

25

Therapeutic classification Antidepressant

\begin{tabular}{ll}
\hline Pharmaceutical & Fluoxetine \\
Acronym & FLX \\
CAS. No. & $54910-89-3$ \\
Molecular formula & $\mathrm{C}_{17} \mathrm{H}_{18} \mathrm{~F}_{3} \mathrm{NO}$ \\
$\mathrm{MW}^{\mathrm{a}}$ & 309.3 \\
$\mathrm{pK}_{\mathrm{a}}^{\mathrm{b}} ; \log K_{\mathrm{ow}}{ }^{\mathrm{c}}$ & $10.06 ; 4.05$
\end{tabular}

Venlafaxine

VFX

93413-69-5

$\mathrm{C}_{17} \mathrm{H}_{27} \mathrm{NO}_{2}$

277.4

$9.40 ; 3.28$

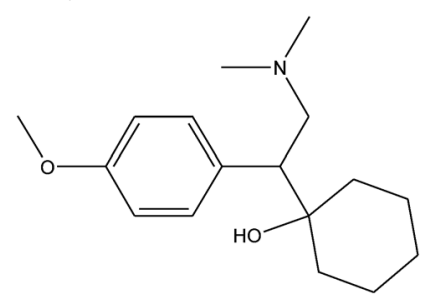

Ref. 
at days $0,1,4,7,10 \ldots$ and 365 and immediately stored at $-20{ }^{\circ} \mathrm{C}$ until HPLC analysis. The beakers were covered by transparent plastics to avoid evaporation. Controlled experiments in dark were performed by keeping samples in boxes and covering with aluminium foil under identical conditions.

\subsection{Instrumental analysis}

The parent pharmaceuticals in aqueous solution were determined by Shimadzu LC-10A Dvp HPLC equipped with a SPD20A detector. Agilent TC-C18 column $(250 \mathrm{~mm} \times 4.6 \mathrm{~mm}$ I.D., $5 \mu \mathrm{m}$ ) was used. The mobile phase was consisted of $10 \mathrm{mM}$ ammonium acetate buffer ( $\mathrm{pH}=4$, formic acid adjusted) and methanol $(10: 90, \mathrm{v} / \mathrm{v})$, working in isocratic mode at a flow rate of $0.8 \mathrm{~mL} \mathrm{~min}{ }^{-1}$. The injection volume was $5 \mu \mathrm{L}$ and the column temperature was kept at $25{ }^{\circ} \mathrm{C}$. Signals were detected by a UV detector at the wavelength of $224 \mathrm{~nm}$ for atenolol, $221 \mathrm{~nm}$ for metoprolol, $214 \mathrm{~nm}$ for propranolol, $227 \mathrm{~nm}$ for fluoxetine and $220 \mathrm{~nm}$ for venlafaxine. The linear range of standard curves was $2 \mathrm{mg} \mathrm{L}^{-1}$ to $100 \mathrm{mg} \mathrm{L}^{-1}$ for all target compounds with linear regression coefficients $\left(R^{2}\right)>0.99$.

The transformation products (TPs) were identified using high-performance liquid chromatography (Ultimate3000 HPLC system, Dionex, USA) followed by electrospray ionization and tandem mass spectrometry (ESI-MS/MS, API3200, AB Sciex, USA). They were separated by Chirobiotic V column $(250 \times 4.6$ mm, I.D. $5 \mu \mathrm{m}$ ) (Advanced Separation Technologies, USA) with a guard column $(20 \times 4.0 \mathrm{~mm}$, I.D. $5 \mu \mathrm{m})$ according to the previous study. ${ }^{26}$ Mobile phase consisted of $90 \%$ methanol, $10 \%$ $\mathrm{H}_{2} \mathrm{O}(0.1 \% \mathrm{HCOOH}, \mathrm{pH}=4)$ at a flow rate of $0.65 \mathrm{~mL} \mathrm{~min}^{-1}$. The column was maintained at $25{ }^{\circ} \mathrm{C}$ with an optimal chromatographic run time $40 \mathrm{~min}$ and the injection volume was 10 $\mu \mathrm{L}$. More information is available in ESI. $\dagger$

\subsection{Molecular structure relationship analysis}

HOF (heat of formation in $\mathrm{kJ} \mathrm{mol}^{-1}$ ), $E_{\text {Hомо }}$ (the energy of the highest occupied molecular orbital in eV), $E_{\text {LUMO }}$ (the energy of the lowest unoccupied molecular orbital in eV), TE (total energy in $\mathrm{eV}$ ) and ( $\left.E_{\mathrm{LUMO}}-E_{\mathrm{HOMO}}\right)$ were calculated in the MOPAC 2016 software. A stepwise multiple liner regression analysis was performed using SPSS v.20.0. The linear least-squares method was used to give the best fit of the predicted $k$ values to the obtained data. Model adequacy was measured by the squared correlation coefficient adjusted for degrees of freedom $\left(r_{\mathrm{adj}}{ }^{2}\right)$, the standard error (SE), the Fisher criterion $(F)$ and the significance level $(p)$.

\section{Results and discussion}

\subsection{Degradation incubation}

The degradation curves of the studied pharmaceuticals fitted pseudo first-order degradation kinetics, described by the following equation:

$$
C_{t}=C_{0} \times \mathrm{e}^{-k t}
$$

where, $C_{t}$ represents the concentration of the analyte at time $t$, $C_{0}$ represents the initial concentration of the analyte, and $k$ is the pseudo first-order degradation rate constant.

The half-lives can be calculated from the degradation rate constant, using the equation below: ${ }^{27}$

$$
t_{1 / 2}=\frac{\ln 2}{k}
$$

For measured $\beta$-blockers and antidepressants in this study, the half-life values varied from several days to more than one hundred days. Table 2 summarizes the half-lives of these pharmaceuticals at different $\mathrm{pH}$ values in ultrapure water in light and dark. The most rapidly degraded pharmaceutical at any $\mathrm{pH}$ values was always propranolol, with half-lives ranging from 5.7 to $28.5 \mathrm{~d}$. While other pharmaceuticals were more persistent, with half-lives of 29.6-78.2 d for metoprolol, 56.381.4 d for atenolol, 46.6-183.2 d for fluoxetine, and 68.8-145.4 $\mathrm{d}$ for venlafaxine. As can be seen from Fig. 1, at the beginning of the reaction, quicker degradation of most pharmaceuticals measured could be observed, while degradation rate decreased slowly as experimental time went by.

In comparison with metoprolol and atenolol, the observed degradation rates of propranolol were fast. The direct photodegradation experiment conducted by Liu et al. ${ }^{22}$ in water under xenon lamp $\left(41 \mathrm{~W} \mathrm{~m}^{-2}\right)$ also indicated propranolol $\left(t_{1 / 2}=16 \mathrm{~h}\right)$ was roughly 20 and 33 times faster than atenolol $\left(t_{1 / 2}=347 \mathrm{~h}\right)$ and metoprolol $\left(t_{1 / 2}=630 \mathrm{~h}\right)$, respectively. For propranolol, as the most photolabile compounds in this study, photodegradation might be the predominant removal process. But it was still frequently detected in river owing to its high use and incomplete removal in STPs. Additionally, Lin et al. ${ }^{28}$ concluded that the photodegradation rate of propranolol in air-saturated purified water with a xenon arc lamp $\left(765 \mathrm{~W} \mathrm{~m}^{-2}\right)$ was 0.227 $\mathrm{h}^{-1}$, approximately 31-155 times faster than that in this study. Similarly, based on experimentally measured quantum yields for direct photolysis, the half-lives of propranolol in bi-distilled water at the highest latitudes $\left(50^{\circ} \mathrm{N}\right)$ in winter was $16.8 \mathrm{~d}$, indicating the irradiation source and intensity have important effects on photolysis rate.

Moreover, it can be inferred that the degradation rates of venlafaxine ranged from $0.0145 \mathrm{~d}^{-1}$ to $0.0069 \mathrm{~d}^{-1}$, approximately 7.6-16 times longer than that in ultrapure water under medium pressure $\mathrm{Hg}$ lamp (approximately $50 \mathrm{~W}$ ). ${ }^{16}$ The halflives of venlafaxine was the longest compared with the other pharmaceuticals, indicating its more degradation-resistance and persistence in controlled laboratory studies, ${ }^{\mathbf{1 6}}$ and thus it is not surprising that venlafaxine is frequently detected in surface waters. ${ }^{10}$ Their persistence analysis can support priority pharmaceutical screening. ${ }^{29,30}$

\subsection{The degradation of the pharmaceuticals in light}

The degradation of $\beta$-blockers and antidepressants in light was performed at different $\mathrm{pH}$ values. As can be seen from Table 2 and Fig. 2, the effect of solution $\mathrm{pH}$ on kinetics of degradation for metoprolol, atenolol and propranolol have significant 
Table 2 Degradation half-lives of selected five pharmaceuticals in ultrapure water at different pH values

\begin{tabular}{|c|c|c|c|c|c|c|c|c|c|c|}
\hline Compounds & \multicolumn{10}{|c|}{$t_{1 / 2}(\mathrm{~d})$} \\
\hline ATN & 64.1 & 683 & 67.9 & 1133 & 56.3 & 7770 & 81.4 & 1724 & 68.2 & 784 \\
\hline MTP & 29.6 & 1076 & 70.7 & 1086 & 48.2 & 1463 & 78.2 & 1781 & 73.6 & 1661 \\
\hline VFX & 145.4 & 1045 & 123.9 & 14002 & 92.9 & 2327 & 74.6 & 1399 & 68.8 & 9746 \\
\hline
\end{tabular}

(a)

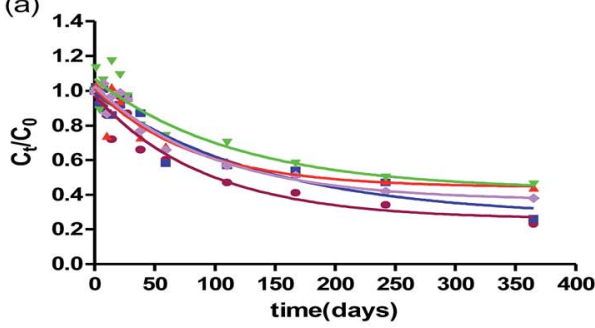

(c)

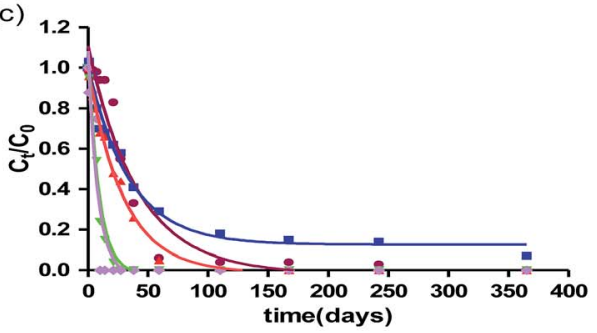

(e)

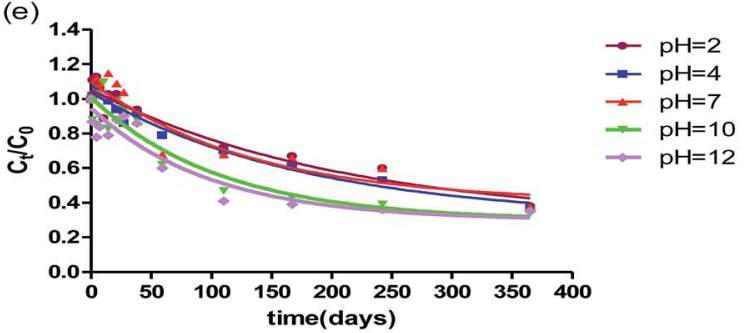

(b)
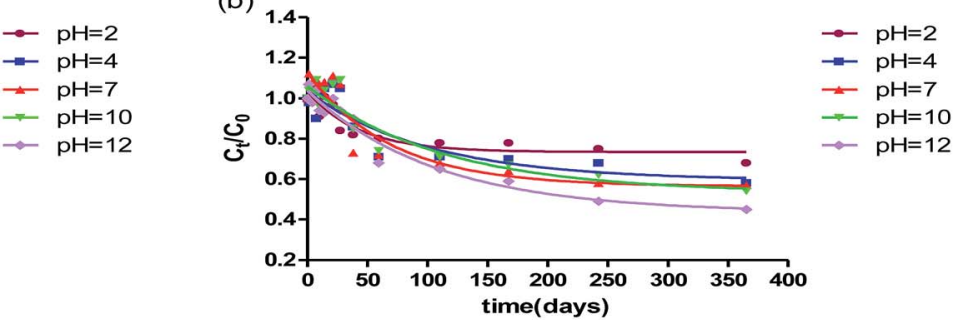

(d)
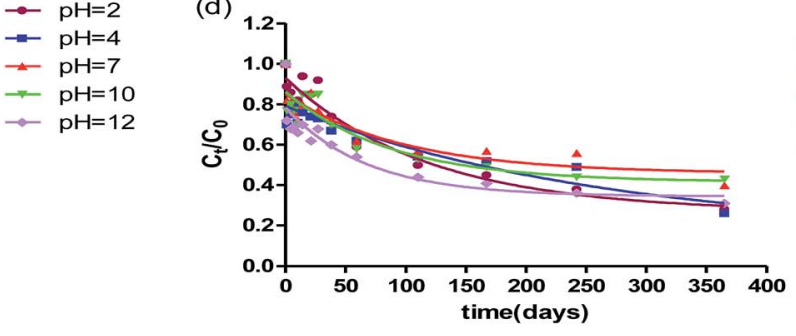

$\rightarrow \mathrm{pH}=2$

$-\mathrm{pH}=4$

$\approx \mathrm{pH}=7$

$\rightarrow \mathrm{pH}=10$

$\rightarrow \mathrm{pH}=12$

g. 1 Pseudo first-order kinetic plot for (a) atenolol, (b) metoprolol, (c) propranolol, (d) fluoxetine and (e) venlafaxine in ultrapure water at different $\mathrm{pH}$ values during a one-year period exposure to fluorescent lamp.

differences although propranolol, metoprolol and atenolol belong to the same therapeutic class. Compared with two other $\beta$-blockers, propranolol was subject to rapid degradation at any $\mathrm{pH}$ values. The degradation rate increased with the increasing $\mathrm{pH}$ values, with the rate constants ranging from 0.024 to 0.122 $\mathrm{d}^{-1}$. As shown in Fig. 2, the degradation rate of propranolol varied slightly between 2 and 7 and increased sharply above pH 7.

The faster degradation of propranolol may be attributed to the differences of its chromophore structure, which has been shown in Table 1. For metoprolol and atenolol, although their $\mathrm{p} K_{\mathrm{a}}$ values were approximate (9.67 and 9.6, respectively), the variation of degradation rate under different $\mathrm{pH}$ values was not consistent. As seen in Table 2, the fastest degradation occurred at pH 2 for metoprolol, with a half-life of $29.6 \mathrm{~d}$, whereas at $\mathrm{pH} 7$ for atenolol, with a half-life of $56.3 \mathrm{~d}$. From data measured in this study, it can be seen that both metoprolol and atenolol were likely persistent at $\mathrm{pH} 10$. The $\mathrm{p} K_{\mathrm{a}}$ value thus is an important parameter for their degradation. At $\mathrm{pH}>\mathrm{p} K_{\mathrm{a}}$, with the increase of $\mathrm{pH}$ value, the degradation rates of both apparently increased. The phenomenon could be partly explained by hydroxyl groups, ${ }^{31}$ which was affected by the solution $\mathrm{pH}$. To some extent, the degradation of propranolol was also attributed to the theory. At $\mathrm{pH}<\mathrm{p} K_{\mathrm{a}}$, no apparent correlations were observed for the degradation of metoprolol and atenolol. The degradation rate of metoprolol was approximate or a little higher, approximately 2.17, 1.17, 1.04 times higher than that of atenolol at $\mathrm{pH}$ 2, 7 and 10, respectively. The result demonstrated that the $\mathrm{pH}$ 


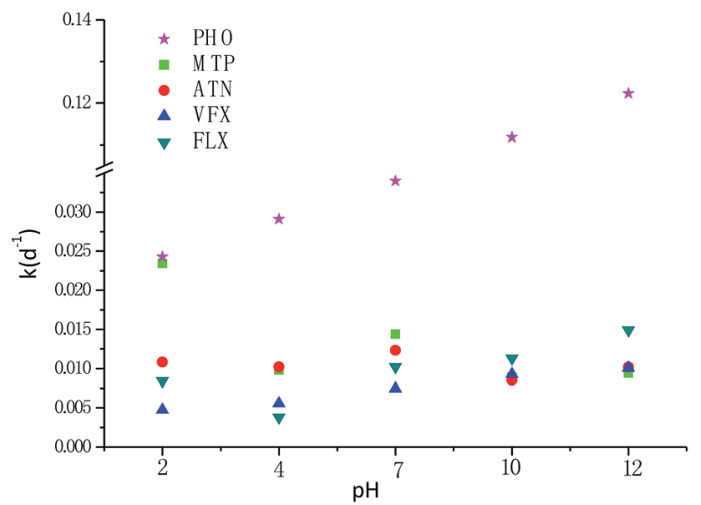

Fig. 2 Effect of $\mathrm{pH}$ values on the degradation rate constants of atenolol, metoprolol, propranolol, fluoxetine and venlafaxine in ultrapure water during one-year period exposure to fluorescent lamp.

values have a complex effect on the degradation. The variation of all three measured $\beta$-blockers at different $\mathrm{pH}$ values in this study was a bit different from the results in other studies. ${ }^{31,32}$ The degradation rate constant of atenolol was higher than that of metoprolol at $\mathrm{pH} 2,{ }^{32}$ which is in contrast with the findings in this study. This indicated that the different conditions can lead to different degradation characteristics. The degradation rate of atenolol was nearly 4 orders of magnitude slower than the value obtained by Salgado et al..$^{33}$ under UV Hg lamp at $\mathrm{pH} 6.4$ in pure water, further indicating the light intensity significantly affected the photodegradation.

For venlafaxine, with increasing $\mathrm{pH}$, the degradation rate increased gradually, which was similar with propranolol. The results were consistent with a previous study, which also showed higher degradation rate at high $\mathrm{pH}$ values, ${ }^{34}$ which could be partly attributed to base-catalyzed mechanism. ${ }^{35}$ Expect for $\mathrm{pH} 2$, the degradation characteristics of fluoxetine was also in accord with the conclusion. For fluoxetine and venlafaxine, the shortest half-lives observed at $\mathrm{pH} 12$ were 46.6 $\mathrm{d}$ and $68.8 \mathrm{~d}$, respectively, which corresponded to the rate constant of $0.0149 \mathrm{~d}^{-1}$ and $0.0100 \mathrm{~d}^{-1}$, respectively.

As shown in Fig. S3, $\uparrow$ at pH 2, 4, 7, and 10 (less or close to the $\mathrm{p} K_{\mathrm{a}}$, Table 1), the absorption did not change much for the same compound. However, under a very high $\mathrm{pH} 12\left(>\mathrm{p} K_{\mathrm{a}}\right)$, the absorption varied greatly, probably due to the effect of deprotonation. The effect of $\mathrm{pH}$ on the degradation was not only attributed to the protonation and deprotonation of functional groups and their different reactivity, but also was ascribed to the light absorption difference.

\subsection{The hydrolytic degradation of the pharmaceuticals in darkness}

To evaluate the effect of hydrolysis of selected pharmaceuticals, the experiments in darkness were also performed. The effect of $\mathrm{pH}$ values on the degradation for atenolol, metoprolol, propranolol, fluoxetine, venlafaxine in water in dark is presented in Fig. S1 (ESI $\dagger$ ). It is observed that in the Fig. 3, the decrease in the concentration of $\beta$-blockers and antidepressants varied significantly. For atenolol, weak acid slightly promoted the hydrolysis and photolysis, which was consistent with fluoxetine. For metoprolol, acidic solution contributed to the hydrolysis but constrained the photolysis.

The degradation in light should be the addition of the contribution of both photodegradation and hydrolysis. Photodegradation contributions to the degradation of propranolol, fluoxetine and venlafaxine were 2.8-5.3 times, 1.3-7.1 times and 1.5-30.5 times, respectively, higher than hydrolysis contributions. For propranolol, hydrolysis played only a small part and showed a slight decrease under strong acidic or alkaline. Kwon et al. ${ }^{19}$ found fluoxetine degraded only by $2-3 \%$ from the initial concentration at different $\mathrm{pH}$ values in the dark. The different degree of hydrolysis is because the degradation duration in this study (365 d) was much longer than that in the study of JeongWook et al. $(30 \mathrm{~d})$. However, it should also be noted that for metoprolol and atenolol at some $\mathrm{pH}$ values, the hydrolysis was higher than photolysis; about $25 \%$ of metoprolol was hydrolysed and about $7 \%$ of metoprolol were photodegraded at $\mathrm{pH} 2$. In another study, atenolol also showed no significant difference in photolysis (decreased by $4.0 \%$ ) and hydrolysis (decreased by $3.5 \%$ ) during the five-day solar exposure. ${ }^{36}$ Except for atenolol, the weak hydrolysis of propranolol, metoprolol, fluoxetine and venlafaxine might be due to a lack of hydrolysable functional group.

Photodegradation has been reported to be a significant degradation pathway for organic pollutants, whereas hydrolysis has usually been overlooked because most previous laboratory experiments were conducted at strengthened conditions, under which a nearly complete degradation could occur in a short time, while hydrolysis might be negligible within such a short time. However, in a long-term degradation process under a mild condition, compared with photodegradation, the hydrolysis could also be very important and cannot be neglected. Yamamoto et $a .^{20}$ found that for propranolol and atenolol, at least $12 \%$ of the initial concentrations degraded at $70 \mathrm{~h}$ in the control samples covered with aluminium foil, while degradation could be significant only after a longer time under mild radiation condition.

\subsection{The effect of molecular structure on degradation}

All the pharmaceuticals degraded following the pseudo firstorder degradation kinetics. The degradation is partly due to the absorption of solar radiation by their aromatic rings, heteroatoms, and other functional chromophore groups. As shown in Fig. S3, $\uparrow$ due to the differences in molecular structures, the UV-vis absorbance of these compounds were different to some extent. The structures of these pharmaceuticals have been shown in Table 1. Propranolol consists of a naphthalene backbone that could lead to a greater overlap between the absorption spectrum and the solar spectrum (shown in Fig. S3†), while metoprolol and atenolol just have a benzoic backbone. So, when irradiated by light, propranolol degraded fastest, followed by metoprolol and atenolol in neutral or weak base solution. Pharmaceuticals generally contain acidic or basic functional groups, such as carboxylic acid, hydroxyl groups, and amines. ${ }^{37}$ Under strong alkaline condition, the hydroxyl groups could be deprotonated, ${ }^{31}$ which led to red shift of the anionic target 

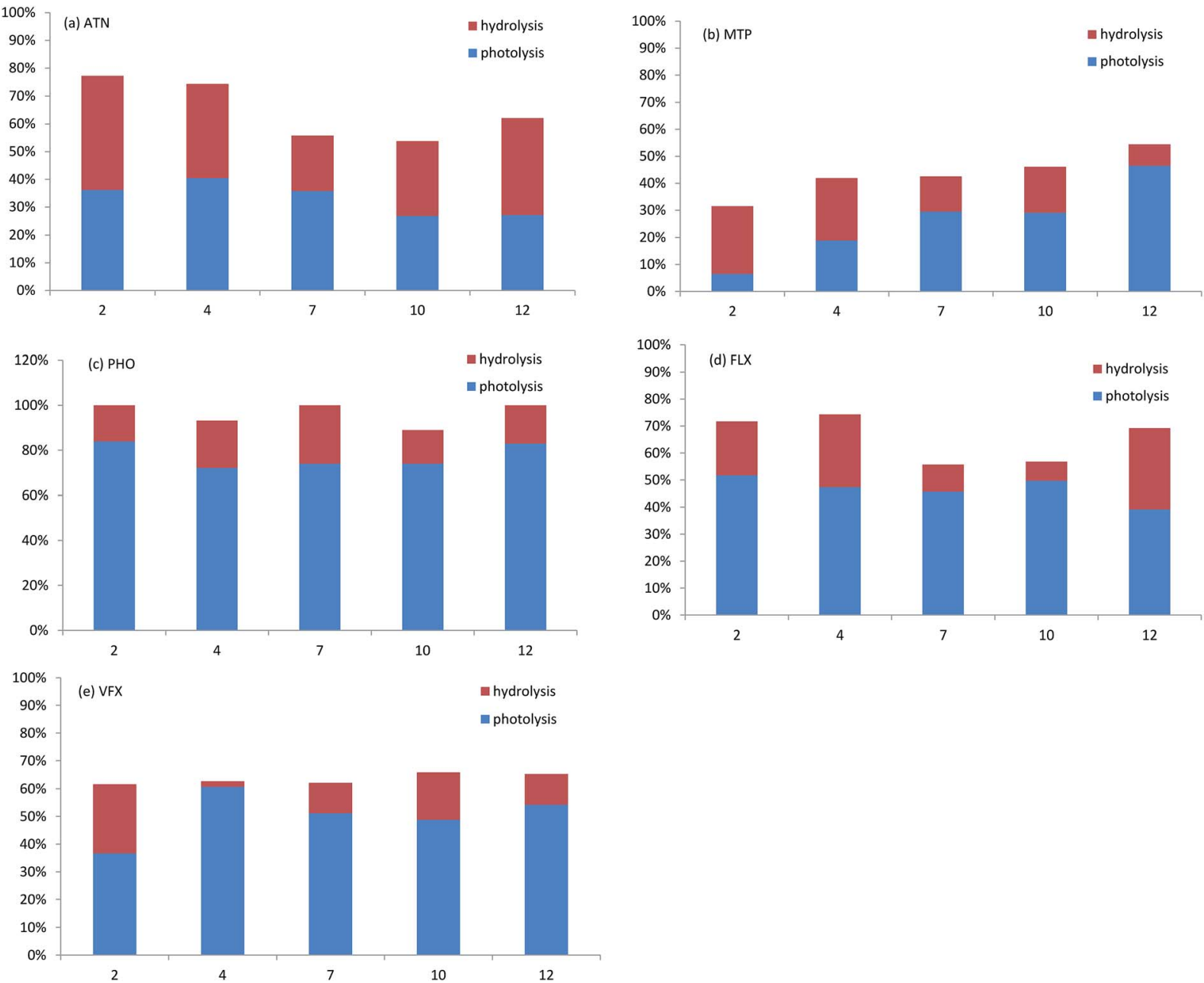

Fig. 3 The overall degradation of ATN, MTP, PHO, FLX, VFX in ultrapure water at different pH values during one-year period exposure to fluorescent lamp.

compounds and the increase of spectrum overlap between the absorption spectrum and the solar spectrum, thereby promoted the degradation of pharmaceuticals. Overall, propranolol was degraded at a higher rate than other compounds under the same conditions, while metoprolol was comparable to or faster than atenolol. In order to further discover the molecular structural relationship with degradation, stepwise linear regression was performed between $k$ (mean value of degradation rate constants among different $\mathrm{pH}$ ) and five quantum chemistry descriptors, leading to the following equation:

$$
k=-0.003\left(E_{\mathrm{LUMO}}-E_{\mathrm{HOMO}}\right)+2.002 \times 10^{-5} \mathrm{TE}+0.996
$$

$$
n=5, r_{\mathrm{adj}}^{2}=0.993, \mathrm{SE}=0.003, F=135.8, p>0.001
$$

Based on the ( $\left.E_{\mathrm{LUMO}}-E_{\mathrm{HOMO}}\right)$ and $\mathrm{TE}$ values presented in ESI $\dagger$ (Table S1), the leave-one-out cross-validation was conducted with $r_{\text {adj }}{ }^{2}$ higher than 0.99. Eqn (3) indicates that mean rate constants has positive correlation with $\mathrm{TE}$ but negative correlation with ( $\left.E_{\mathrm{LUMO}}-E_{\mathrm{HOMO}}\right)$. TE can be used as a significant parameter reflecting the stability of a molecule. The higher the total energy is, the less stable the molecule is, and the higher degradation rate constants. Generally, the difference between $E_{\mathrm{LUMO}}$ and $E_{\mathrm{HOMO}}$ is defined as bandgap, a parameter measuring whether the molecule are easily excited or not. The smaller bandgap means easier molecular excitation, and hence causes higher degradation rate constant. $k$ in eqn (3) can reflect the general degradation trend of PPCPs. Because eqn (3) is just based on five sets available data, more data should be further available to validate and amend the model.

\subsection{Characteristics of typical transformation products}

The TPs of these five pharmaceuticals are chiral compounds, which may possess stereoselectivity in their pharmacology and pharmacodynamics. The chirality of a compound means it can exist as two non-superimposable mirror image forms-similar to our left and right hands. ${ }^{38}$ These two forms are designated as $(+)$ and (-) enantiomers. However, the elution order of the enantiomers of these TPs could not be determined because the enantiomercally pure forms of these TPs were unavailable. 

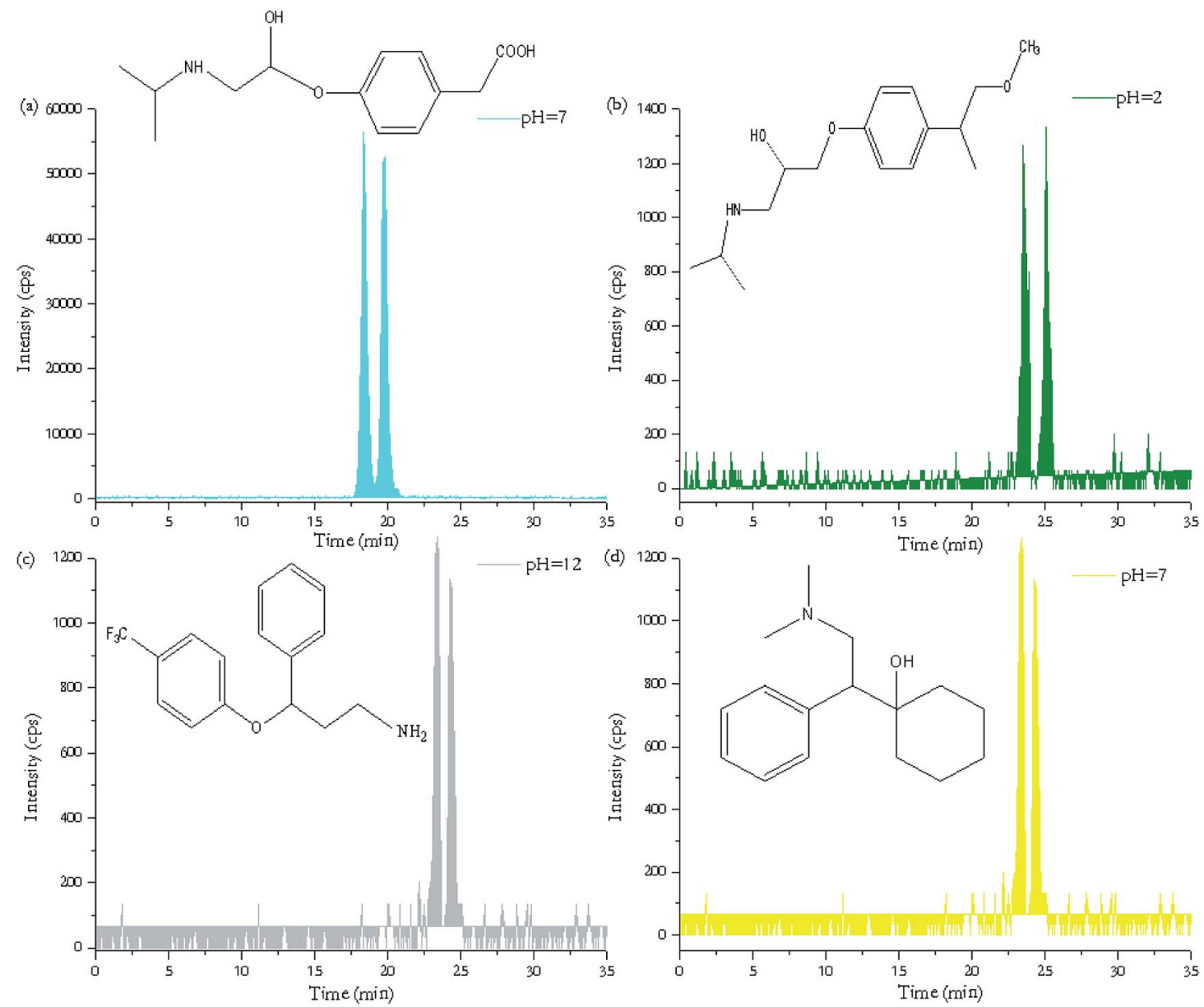

Fig. 4 HPLC-MS/MS separation of transformation products of ATN (a), MTP (b), FLX (c), VFX (d) with chiral column.

Therefore, the first and second eluted enantiomers of TPs are respectively referred to and $\mathrm{E} 1$ and $\mathrm{E} 2 .{ }^{39}$ Stereoselectivity usually remains unchanged during physiochemical process, such as photodegradation and hydrolysis, which can be shown in Fig. 4. To get more insights on degradation of five pharmaceuticals, chromatograms of TPs were determined by HPLC-MS/MS at enantiomeric level (Fig. 4). With different $\mathrm{pH}$ values, the concentrations of TPs of five target pharmaceuticals, shown in Table S4 (ESI $\dagger$ ), were within a large variation range from several micrograms to several milligrams. Fig. 4(a) and (b) shows the formation of the degradation products of ATN and MTP: metoprolol acid and $\alpha$-hydroxymetoprolol, respectively. $\alpha$ Hydroxymetoprolol was not detected at $\mathrm{pH} 7,10,12$ but occurred at pH 2, 4 with the concentration less than $150 \mu \mathrm{g} \mathrm{L}{ }^{-1}$, whereas metoprolol acid could be detected at any $\mathrm{pH}$ values, with concentrations up to several hundred $\mu \mathrm{g} \mathrm{L}^{-1}$.

Norfluoxetine, as the major degradation products of fluoxetine, were only identified at $\mathrm{pH} 10$ and $\mathrm{pH} 12$ in samples. As can be seen from Fig. 4(c), the intensity of norfluoxetine was relatively low because norfluoxetine formed by photolysis from fluoxetine continues to be photodegraded to other photoproducts. ${ }^{40} \mathrm{O}$-Desmethyl metabolite of venlafaxine (seen in Fig. 4(d)), as an active metabolite, have been found to be rapidly degraded in the in situ degradation experiment by photolysis. ${ }^{41}$
Although degradation of PHO was observed, we did not detect its TP 4-OH-propranolol in the last sampling which could be due to its instability and further degradation over the long period.

\section{Conclusions}

In this study, one-year degradation of three $\beta$-blockers and two antidepressants were studied at $\mathrm{pH}$ values in the range of 2-12 in an artificial climate incubator. The degradability of selected five pharmaceuticals under different $\mathrm{pH}$ values has been found to vary significantly, with some degraded rapidly and some to a limited extent, with half-lives of 5.7-28.5 d for propranolol, 29.6-78.2 d for metoprolol, 56.3-81.4 d for atenolol, 46.6-183.2 $\mathrm{d}$ for fluoxetine, and 68.8-145.4 d for venlafaxine. As a result, the $\mathrm{pH}$, as an important parameter, played a key role in the degradation. At the beginning of the reaction, high degradation rates of most pharmaceuticals could be observed, while degradation reaction decreased slowly with the irradiation time. In present study, half-lives of the target pharmaceuticals under fluorescent lamp were almost all above $29 \mathrm{~d}$, except for propranolol. In particularly, fluoxetine was most persistent at $\mathrm{pH} 4$, with half-lives up to $183.2 \mathrm{~d}$, while propranolol was most easily degradable, with half-lives varying from $5.7 \mathrm{~d}$ to $28.5 \mathrm{~d}$. 
This study also concluded that both photolysis and hydrolysis contributed to the degradation of the pharmaceuticals, although the degradation occurred in the presence of light at a higher rate than in the dark. To more accurately assess the environmental fate of pharmaceuticals, it is necessary to take the synergistic effects of both hydrolysis and photolysis into consideration. In addition, typical transformation products were detected and were identified as metoprolol acid, $\alpha$ hydroxymetoprolol, norfluoxetine and $O$-desmethylvenlafaxine. Lots of photodegradation products have not been identified in the aquatic environment due to the limitation of analytical methods and lack of available standards. Further investigations of such TPs are necessary for a comprehensive environmental risk assessment of such pharmaceuticals.

The findings in this study could not only help to understand the degradation and fate of pharmaceuticals but also provide the fundamental data for persistence assessment.

\section{Acknowledgements}

This work was financially supported by the National Natural Science Foundation of China (21577075), Tsinghua University Initiative Scientific Research Program (20131089193), and Program for Changjiang Scholars and Innovative Research Team in University (IRT1261).

\section{Notes and references}

1 B. Subedi and K. Kannan, Sci. Total Environ., 2015, 514, 273-280.

2 D. R. Baker and B. Kasprzyk-Hordern, Sci. Total Environ., 2013, 454-455, 442-456.

3 G. Dai, B. Wang, J. Huang, R. Dong, S. Deng and G. Yu, Chemosphere, 2015, 119, 1033-1039.

4 M. M. Schultz, E. T. Furlong, D. W. Kolpin, S. L. Werner, H. L. Schoenfuss, L. B. Barber, V. S. Blazer, D. O. Norris and A. M. Vajda, Environ. Sci. Technol., 2010, 44, 1918-1925.

5 A. Y.-C. Lin, T.-H. Yu and C.-F. Lin, Chemosphere, 2008, 74, 131-141.

6 N. A. Alygizakis, P. Gago-Ferrero, V. L. Borova, A. Pavlidou, I. Hatzianestis and N. S. Thomaidis, Sci. Total Environ., 2016, 541, 1097-1105.

7 N. H. Tran, J. Hu and S. L. Ong, Talanta, 2013, 113, 82-92.

8 S. Mompelat, B. Le Bot and O. Thomas, Environ. Int., 2009, 35, 803-814.

9 V. de Jesus Gaffney, C. M. M. Almeida, A. Rodrigues, E. Ferreira, M. J. Benoliel and V. V. Cardoso, Water Res., 2015, 72, 199-208.

10 C. D. Metcalfe, S. Chu, C. Judt, H. Li, K. D. Oakes, M. R. Servos and D. M. Andrews, Environ. Toxicol. Chem., 2010, 29, 79-89.

11 R. Feito, Y. Valcárcel and M. Catalá, Chemosphere, 2013, 90, 2065-2069.

12 F. De Andres, G. Castaneda and A. Rios, Chirality, 2009, 21, 751-759.

13 J. K. Stanley, A. J. Ramirez, M. Mottaleb, C. K. Chambliss and B. W. Brooks, Environ. Toxicol. Chem., 2006, 25, 1780-1786.

14 S. Yan and W. Song, Environ. Sci.: Processes Impacts, 2014, 16, 697-720.
15 D. Fatta-Kassinos, M. I. Vasquez and K. Kümmerer, Chemosphere, 2011, 85, 693-709.

16 P. C. Rúa-Gómez and W. Püttmann, Chemosphere, 2013, 90, 1952-1959.

17 A. Piram, A. Salvador, C. Verne, B. Herbreteau and R. Faure, Chemosphere, 2008, 73, 1265-1271.

18 Q.-T. Liu, R. I. Cumming and A. D. Sharpe, Photochem. Photobiol. Sci., 2009, 8, 768-777.

19 J. W. Kwon and K. L. Armbrust, Environ. Toxicol. Chem., 2006, 25, 2561-2568.

20 H. Yamamoto, Y. Nakamura, S. Moriguchi, Y. Nakamura, Y. Honda, I. Tamura, Y. Hirata, A. Hayashi and J. Sekizawa, Water Res., 2009, 43, 351-362.

21 R. Andreozzi, R. Marotta and N. Paxéus, Chemosphere, 2003, 50, 1319-1330.

22 Q.-T. Liu and H. E. Williams, Environ. Sci. Technol., 2007, 41, 803-810.

23 P. F. Robinson, Q.-T. Liu, A. M. Riddle and R. Murray-Smith, Chemosphere, 2007, 66, 757-766.

24 T. Qiao, Z. Yu, X. Zhang and D. W. Au, J. Environ. Monit., 2011, 13, 3097-3103.

25 H. Li, P. A. Helm, G. Paterson and C. D. Metcalfe, Chemosphere, 2011, 83, 271-280.

26 R. Ma, B. Wang, S. Lu, Y. Zhang, L. Yin, J. Huang, S. Deng, Y. Wang and G. Yu, Sci. Total Environ., 2016, 557-558, 268-275.

27 L. Araujo, N. Villa, N. Camargo, M. Bustos, T. García and A. De Jesus Prieto, Environ. Chem. Lett., 2011, 9, 13-18.

28 A. Y.-C. Lin, C.-A. Lin, H.-H. Tung and N. S. Chary, J. Hazard. Mater., 2010, 183, 242-250.

29 P. D. Voogt, M.-L. Janex-Habibi, F. Sacher, L. Puijker and M. Mons, Water Sci. Technol., 2009, 59, 39-46.

30 A. Ginebreda, A. Jelić, M. Petrović, M. L. De Alda and D. Barceló, Environ. Sci. Pollut. Res., 2012, 19, 958-970.

31 E. Hapeshi, A. Achilleos, M. Vasquez, C. Michael, N. Xekoukoulotakis, D. Mantzavinos and D. Kassinos, Water Res., 2010, 44, 1737-1746.

32 H. Yang, T. An, G. Li, W. Song, W. J. Cooper, H. Luo and X. Guo, J. Hazard. Mater., 2010, 179, 834-839.

33 R. Salgado, V. Pereira, G. Carvalho, R. Soeiro, V. Gaffney, C. Almeida, V. V. Cardoso, E. Ferreira, M. Benoliel and T. Ternes, J. Hazard. Mater., 2013, 244, 516-527.

34 X. Li, Y. Wang, J. Zhao, H. Wang, B. Wang, J. Huang, S. Deng and G. Yu, J. Hazard. Mater., 2015, 300, 298-306.

35 M. W. Lam, C. J. Young and S. A. Mabury, Environ. Sci. Technol., 2005, 39, 513-522.

36 M. M. Dong, R. Trenholm and F. L. Rosario-Ortiz, J. Hazard. Mater., 2015, 282, 216-223.

37 W. A. Arnold and K. McNeill, Analysis, Fate and Removal of Pharmaceuticals in the Water Cycle, 2007, pp. 361-385.

38 T. Harner, K. Wiberg and R. Norstrom, Environ. Sci. Technol., 2000, 34, 218-220.

39 V. K. H. Barclay, N. L. Tyrefors, I. M. Johansson and C. E. Pettersson, J. Chromatogr. A, 2011, 1218, 5587-5596.

$40 \mathrm{~J}$-W. Kwon and K. L. Armbrust, Environ. Toxicol. Chem., 2006, 25, 2561-2568.

41 S. Rühmland, A. Wick, T. A. Ternes and M. Barjenbruch, Ecol. Eng., 2015, 80, 125-139. 